E3S Web of Conferences 1, 19005 (2013)

DOI: $10.1051 / \mathrm{e} 3$ sconf/20130119005

(c) Owned by the authors, published by EDP Sciences, 2013

\title{
Leaching of Trace Metals from Soil under Alternating Oxic-anoxic Conditions: a Column Study
}

\author{
$\underline{\text { R. Balint Nimirciag }}{ }^{1,2}$, E. Buratto ${ }^{3}$ and F. Ajmone-Marsan ${ }^{3}$ \\ 1 "Politehnica" University of Bucharest, 011061, Bucharest, Romania, ramona.nimirciag@unito.it. \\ ${ }^{2}$ Geological Institute of Romania, 012271, Bucharest, Romania, ramona.balint@igr.ro \\ ${ }^{3}$ Di.Va.P.R.A - Chimica Agraria, University of Turin, 10095, Grugliasco, Turin, Italy, buerico@libero.it \\ ${ }^{3}$ Di.Va.P.R.A - Chimica Agraria, University of Turin, 10095, Grugliasco, Turin, Italy, franco.ajmonemarsan@unito.it.
}

\begin{abstract}
One of the most important and abundant transition metals in the Earth's crust is iron, which plays a key role in environmental biogeochemistry. A large number of trace metals and other contaminants are associated to $\mathrm{Fe}$ (III) minerals; under anoxic conditions, Fe(III) can be reduced and, consequently, potentially dangerous compounds can be released. In this work we present column experiments of metal mobilization from soils sampled from a mining area in Northeastern Romania. A preliminary study was carried out to determine the extractability of metals in $\mathrm{CaCl}_{2} 0.01 \mathrm{M}$ solution and the influence of adding $1 \mathrm{~g} \mathrm{~L}^{-1}$ lactose as a carbon source. The results showed that the heavy metals were rapidly brought into solution in the medium supplemented with lactose. Then, the release of metals was studied using columns packed with soil percolated with the $\mathrm{CaCl}_{2}$ solution. It was observed that, while $\mathrm{Zn}$ and $\mathrm{Pb}$ are released in the solution congruently with the reduction of $\mathrm{Fe}$ and $\mathrm{Mn}$, copper is mobilized immediately and can be found in the leachate. This suggests that, under alternating oxic-anoxic conditions, the soil can become a source of contamination.
\end{abstract}

Key words: Column study, heavy metals, leachate, redox transformations

\section{Introduction}

Metal mining, smelting, industrial processing and waste disposal result in heavy metal inputs into the environment. Heavy metals are sorbed and retained by the soil, leading to their accumulation. However, the capacity of soil to store these toxic metals is, unfortunately, not infinite (Bridges and Van Baren, 1997). Unlike most other organic pollutants, heavy metals cannot be degraded chemically or biologically. Part of the retention capacity of the soil relies on Fe and Mn oxides that can adsorb the metals on their surface or incorporate them into their mineral structure. Under anaerobic conditions, however, microorganisms can interact with the oxides. As a result $\mathrm{Fe}$ and $\mathrm{Mn}$ oxides become more soluble and bring the metals that are associated with them into solution.

Usually the organic substrates in the soil system act as electron donors coupled with ionic substances (Marsh and MccInterney, 2001). For example, Ayyasamy and Lee (2009) studied the influence of glucose, humic acid and ADQS (anthraquinone-2,6-disulphonate) on the release of heavy metals from soil columns, in the presence of Shewanella sp. They concluded that the highest rate of dissolution of heavy metals in soil was higher in the experiments carried out with glucose (30 $\mathrm{mM})$ and $\mathrm{ADQS}\left(1 \mathrm{mg} \mathrm{L}^{-1}\right)$ as an electron transporter.

Column tests prove to be un useful tool for understanding the behaviour of heavy metals in soil, especially their mobility, transport and fate. Jean-Soro et al (2012) evaluated the leaching of metals from an industrial soil using citric acid and EDTA by column studies. The mobility of heavy metals in two different types of soil using column tests was assessed also by Kowalkowski et al (2010), using $\mathrm{CaCl}_{2} 0.01 \mathrm{M}$ as the leaching solution.

As pointed out by Borch et al. (2010), the quantitative understanding of contaminant fate in fully oxic soils or permanently reducing environments has received much interest in research studies. However, far less attention has been given to the biogeochemical functioning of systems characterized by fluctuating conditions. Microbiological communities, mineral assemblages and redox species may differ greatly from those encountered in permanently oxic or anoxic environments. The aim of this work is to study the effects 
of redox changes on contaminant release and transport.

\section{Materials and Methods}

Two soil samples were obtained by mixing 5 subsamples collected at a depth of about $20 \mathrm{~cm}$. The sampling point is a mining area in the Eastern Carpathians, Romania, where copper ore had been extracted over a long period of time. The samples were air-dried and then passed through $2 \mathrm{~mm}$ sieve. For chemical analysis, the soil was ground up to pass through $0.5 \mathrm{~mm}$ stainles steel mesh.

The texture of the soil samples was determined and the soils were classified as loam/sandy loam. Other properties are detailed in Table 1. The soil $\mathrm{pH}$ was determined after $2 \mathrm{~h}$ agitation at $180 \mathrm{rpm}$ and $15 \mathrm{~min}$ sedimentation of a suspension of $10 \mathrm{~g}$ of soil in $25 \mathrm{~mL}$ of $\mathrm{KCl} 1 \mathrm{M}$. The organic content of the soil (and $\mathrm{C} / \mathrm{N}$ ratio) was also determined.

Table 1. Selected soil properties

\begin{tabular}{|l|l|l|l|l|}
\hline Sample & $\mathrm{pH}$ & Humidity \% & $\mathrm{C} \%$ & $\mathrm{~N} \%$ \\
\hline B1PS & 4.85 & 2.5 & 2.7 & 0.26 \\
\hline B2PS & 5.24 & 2.6 & 4.8 & 0.42 \\
\hline
\end{tabular}

The soil pseudo-total content of $\mathrm{Fe}, \mathrm{Mn}, \mathrm{Cu}, \mathrm{Zn}$ and $\mathrm{Pb}$ was determined after an acid digestion procedure using $10 \mathrm{~mL}$ aqua regia $\left(\mathrm{HCl}: \mathrm{HNO}_{3} 3: 1 \mathrm{v} / \mathrm{v}\right)$ in a Teflon beaker which were added to $1 \mathrm{~g}$ of soil, digested at room temperature for $16 \mathrm{~h}$ and then heated in a microwave oven at $180^{\circ} \mathrm{C}$ for $20 \mathrm{~min}$. The mixture was then transferred quantitativley to a volumetric flask and made up to $50 \mathrm{~mL}$ with deionized water. The metals were analysed by flame atomic absorbtion spectrometer. The extractions in aqua regia were carried out in duplicate.

Batch tests were also performed for the extraction of heavy metals from soil using DCB (dithionite-citratebicarbonate) and ammonium oxalate. Fifty $\mathrm{mL}$ of the prepared solutions were added to $1 \mathrm{~g}$ of soil, shaken for $16 \mathrm{~h}$ at $180 \mathrm{rpm}$, centrifuged and analysed by FAAS. DCB is expected to extract the so called free-iron i.e. the Fe which is not in the silicate minerals. The ammonum oxalate at $\mathrm{pH} 3$ complexes $\mathrm{Fe}$ and $\mathrm{Al}$ of the amorphous oxides and associated to the organic substances.

Since the location and the physico-chemical characteristics of the soil were similar, the soil samples were mixed and $20 \%(\mathrm{v} / \mathrm{v})$ of perlite was added to increase the porosity of the soil and facilitate the percolation. The metals in the mixed soil were extracted with $\mathrm{CaCl}_{2} 0.01 \mathrm{M}$ by adding $30 \mathrm{~mL}$ solution to $10 \mathrm{~g}$ of soil, shaking for $2 \mathrm{~h}$ at $180 \mathrm{rpm}$, centrifuging and analysing by FAAS.

Column tests were performed during 23 days in 70 $\mathrm{cm}$ high and $7 \mathrm{~cm}$ diameter Plexiglass columns. Two colums were filled with $1850 \mathrm{~g}$ mixture of soil and perlite each and a volume of $1300 \mathrm{~mL}$ of $\mathrm{CaCl}_{2} \quad 0.01 \mathrm{M}$ and lactose $1 \mathrm{~g} \mathrm{~L}^{-1}$ was added from underneath, so that the soil would be completely submerged. Anoxic conditions were obtained by flushing the columns with $\mathrm{N}_{2}$ for about 30 seconds, then they were closed tightly to avoid entrance of air. The columns are equipped with 2 rhizon samplers each, at two different heights, the higher at 15 $\mathrm{cm}$ and the lower at $30 \mathrm{~cm}$ depth from the surface of the soil, in order to assess the mobility and transport of heavy metals in the soil solution. Also, the bottom of the columns were provided with filters to avoid loss of material during the periodic leaching.

The soil solution was sampled using the lower and the higher rhizon samplers during the $2^{\text {nd }}, 7^{\text {th }}, 10^{\text {th }}, 14^{\text {th }}$, $16^{\text {th }}, 21^{\text {st }}$ and $23^{\text {rd }}$ days of the experiment and the percolations, i.e. emptying of the column, were performed in the $2^{\text {nd }}, 9^{\text {th }}, 16^{\text {th }}$ and $23^{\text {rd }}$ day of the experiment. $\mathrm{Eh}$ and $\mathrm{pH}$ of the leachate were also monitored. After each percolation, the soil was kept under oxic conditions for three days then the columns were refilled with the volume of fresh solution that had been extracted.

\section{Results and Discussion}

The preliminary results show that the concentration of heavy metals extracted with aqua regia are higher than normal values in soil, which might be due to anthropogenic activities or to the parent rock. DCB extraction gives information on the amount of metals that could be mobilized from the soil, while oxalate points out the concentration of metals in amorphous state or linked to organic substances. The values are summarized in table 2 .

The amount of $\mathrm{Fe}, \mathrm{Mn}, \mathrm{Zn}, \mathrm{Cu}$ and $\mathrm{Pb}$ in the $0.01 \mathrm{M}$ $\mathrm{CaCl}_{2}$ solution was $0.3,6.6,1.0,0.2$ and $0.4 \mathrm{mg} \mathrm{kg}^{-1}$, respectively. The addition of lactose enhances the release of metals, as compared to the single use of $\mathrm{CaCl}_{2}$ (Fig 1). This is also confirmed by the work of Ayyasamy and Lee (2009), who used glucose in the presence of Shewanella $s p$., with better results than without the carbon source.

Table 2. Concentration of metals in soil extracted with different reagents (AR - aqua regia, DCB - dithionite-citratebicarbonate, $\mathrm{Ox}$ - oxalate)

\begin{tabular}{|c|c|c|c|c|c|c|c|c|c|c|c|c|c|c|}
\hline \multirow[b]{2}{*}{ Sample } & \multicolumn{3}{|c|}{$\mathrm{Fe}(\mathrm{g} / \mathrm{kg})$} & \multicolumn{3}{|c|}{$\mathrm{Mn}(\mathrm{mg} / \mathrm{kg})$} & \multicolumn{3}{|c|}{$\mathrm{Cu}(\mathrm{mg} / \mathrm{kg})$} & \multicolumn{3}{|c|}{$\mathrm{Zn}(\mathrm{mg} / \mathrm{kg})$} & \multicolumn{2}{|c|}{$\mathrm{Pb}(\mathrm{mg} / \mathrm{kg})$} \\
\hline & AR & DCB & Ox & $\mathrm{AR}$ & DCB & $\mathrm{Ox}$ & AR & DCB & Ox & AR & DCB & Ox & AR & $\mathrm{DCB}$ \\
\hline B1PS & 41.5 & 11.8 & 4.7 & 1719 & 615 & 434 & 64.5 & 11.3 & 28.7 & 119 & 68.8 & 6.8 & 37.6 & 3.9 \\
\hline B2PS & 43 & 11.2 & 5.3 & 1254 & 690 & 605 & 139.7 & 33.3 & 83.8 & 176.4 & 87.5 & 39.8 & 54.9 & 14.8 \\
\hline
\end{tabular}






Fig 1. Different release of $\mathrm{Fe}, \mathrm{Mn}(\mathrm{a})$ and $\mathrm{Zn}, \mathrm{Cu}$ and $\mathrm{Pb}$ (b) by means of $\mathrm{CaCl}_{2}$ andCaCl $\mathrm{Cl}_{2}$ with lactose.

The influence of lactose on the redox transformations in soil is suggested by the decrease in Eh after only three days of contact with the solution, while, in the absence of the carbon source, the reduction occurs in a much slower pace (Fig 2). The rate of mobilization of heavy metals increased drastically when the solution had a low redox potential.



Fig. 2. The effect of lactose on the redox potential of the soil.

The solubility and mobility of metals in the soil columns was monitored during the 23 days of the study. The results showed that the mobilization of iron and manganese occurred and increased concentrations were observed in the samples taken from the lower rhizon than the higher one, with Fe II trend dependent on the phases of filling/emptying the columns with solution (Fig 3). The system presented an oscillating behaviour regarding the metal release, consistent with the results of Di Palma and Mecozzi (2010). These variations may indicate that equilibrium conditions were not achieved.

A similar trend was observed for both $\mathrm{Pb}$ and $\mathrm{Zn}$, suggesting that reduction processes in soil causes the mobilization of elements with which iron formed mineral associations. Copper showed an opposite behavior, with concentrations decreasing constantly in the samples collected from the rhizon, as compared with reduced iron. However, in the percolated solution, $\mathrm{Cu}$ was the metal whose concentration increased dramatically during the entire period of the experiment (Fig 4). This suggest that soil submerged for a length of time similar to the one experimented can become a source of $\mathrm{Cu}$ contamination for the groundwater.

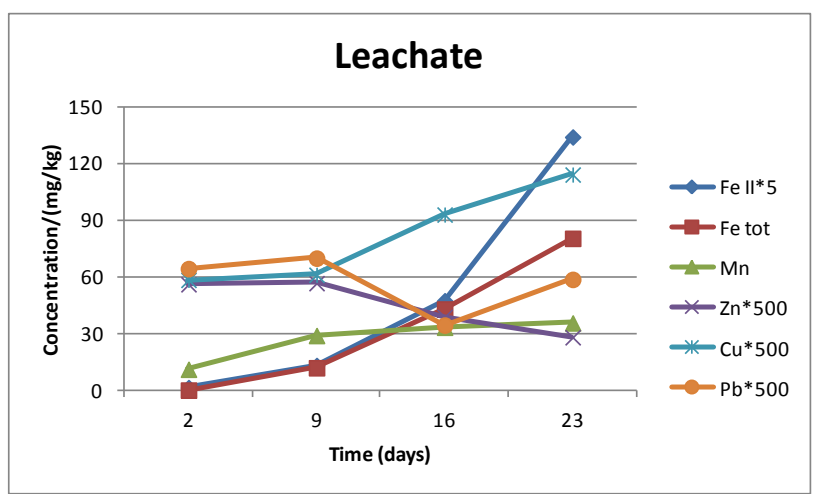

Fig. 4. Metal variability in time in the solution leached from the soil column

\section{Conclusion}

Batch and column tests performed on a soil affected by mining activities have pointed out that metal mobilization may be generated by the variation of ambient parameters such as lowering the redox potential and increasing the amount of carbon in soil. The rate of heavy metal release was higher in solution containing $1 \mathrm{~g} \mathrm{~L}^{-1}$ lactose than just $\mathrm{CaCl}_{2}$ 0.1 M. Among the metals in the soil, Fe and $\mathrm{Mn}$ showed higher levels of dissolution and a clear transport to the lower part of the column than the other heavy metals. Fe and Mn tend to co-precipitate with the other components under aerobic conditions in easily soluble forms which are dissolved in the following anoxic step. This mechanism improved significantly the release of the other metals.

In conclusion, soils submitted to successive aerobicanaerobic conditions, may release heavy metals in the environment, potentially acting as sources of contamination.

\section{Acknowledgements}

The authors wish to acknowledge the support of Di.Va.P.R.A. - Chimica Agraria, University of Turin, Italy, as well as the financing from the "Politehnica" 

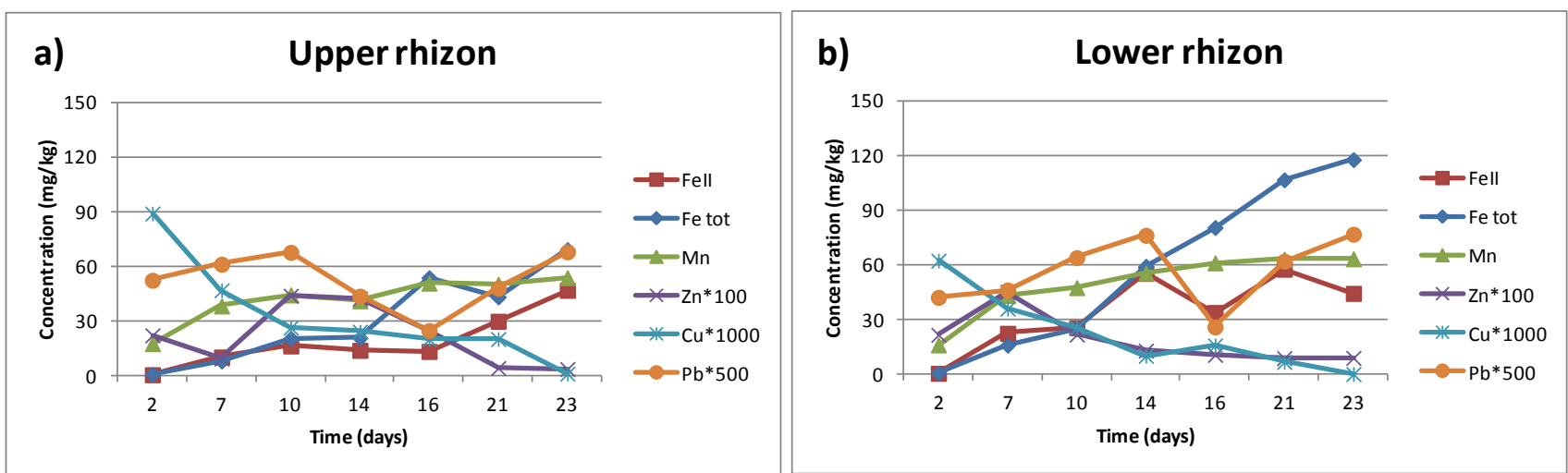

Fig 3. Metal variability in time in the solution extracted from the upper rhizon (a) and lower rhizon (b).

University of Bucharest through the European project: Doctoral scholarship - investments in researchinnovation-development for the future (DocInvest POSDRU/107/1.5/S/76813).

\section{References}

Ayyasamy PM, Lee S. Redox transformation and biogeochemical interaction of heavy metals in Korean soil using different treatment columns in the presence of Shewanella sp. Chemosphere 2009; 77:501-509.

Borch T, Kretzschmar R, Kappler A, Van Cappellen P, Ginder-Vogel M, Voegelin A, Campbell K. Biogeochemical Redox Processes and their Impacton Contaminant Dynamics. Environ. Sci. Technol 2010; 44:15-23.

Bridges EM, Van Baren JHV. Soil: an overlooked, undervalued and vital part of the human environment. Environmentalist 1997; 17: 15-20.
Di Palma L, Mecozzi R. Batch and column tests of metal mobilization in soil impacted by landfill leachate. Waste Management 2010; 30:1594-1599.

Jean-Soro L, Bordas F, Bollinger J-C. Column leaching of chromium and nikel from a contaminated soil using EDTA and citric acid. Environmental Pollution 2012; 164:175-181.

Kowalkowski T, Tutu H, Cozmuta LM, Sprynskyy M, Cukrowska EM, Buszewski B. Assessment of mobility of heavy metals in two soil types by use of column leaching experiments and chemometric evaluation of elution curves. Int. J. of Environmental Analytical Chemistry 2010; 90: 10:797-811.

Marsh TL, McInterney MJ. Relationship of hydrogen bioavailability to chromate reduction in aquifer sediments. Appl. Environ. Microbiol. 2001; 67: $1517-1521$. 